This item was submitted to Loughborough's Research Repository by the author.

Items in Figshare are protected by copyright, with all rights reserved, unless otherwise indicated.

\title{
'When food kills': a socio-technical systems analysis of the UK Pennington 1996 and 2005 E. coli O157 Outbreak Reports
}

PLEASE CITE THE PUBLISHED VERSION

http://dx.doi.org/10.1016/j.ssci.2016.02.007

\section{PUBLISHER}

(C) Elsevier

\section{VERSION}

AM (Accepted Manuscript)

\section{PUBLISHER STATEMENT}

This work is made available according to the conditions of the Creative Commons Attribution-NonCommercialNoDerivatives 4.0 International (CC BY-NC-ND 4.0) licence. Full details of this licence are available at: https://creativecommons.org/licenses/by-nc-nd/4.0/

\section{LICENCE}

CC BY-NC-ND 4.0

\section{REPOSITORY RECORD}

Nayak, Rounaq, and Patrick Waterson. 2016. "'when Food Kills': A Socio-technical Systems Analysis of the UK Pennington 1996 and 2005 E. Coli 0157 Outbreak Reports". Loughborough University. https://hdl.handle.net/2134/21539. 
'When Food Kills': A Socio-technical Systems Analysis of the UK Pennington 1996 and 2005 E.coli 0157 Outbreak Reports

\author{
Rounaq Nayak and Patrick Waterson \\ Human Factors and Complex Systems Group, \\ Loughborough Design School, Loughborough University, \\ Loughborough, LE11 3TU, UK \\ SAFETY-D-15-00620R1 $2^{\text {nd }}$ Revision
}

Corresponding author: Rounaq Nayak. Tel: +44 (0)7908 138057. E-mail:

R.S.Nayak@lboro.ac.uk. Address: Loughborough Design School, Loughborough University, Loughborough, Leicestershire, LE11 3TU, UK 


\section{Abstract}

In 1996 and 2005, two of the largest E.coli 0157 outbreaks occurred in the UK. Many people were infected after consuming meat resulting in a number of deaths. In the present study we applied a systems approach to both the outbreak reports to analyse and compare the accidents. Using the Accimap method of systems analysis, this study investigates the human errors and organisational issues involved in the outbreaks and why accidents such as these occur in the food production domain. The systems analysis carried out in this study on the two outbreaks indicates that there are both common as well as unique factors associated with the two outbreaks. The study concludes that it is necessary to address food safety and look at the food industry as a whole, identify and solve the various problems that could arise in the system, pre-incubation period, before the outbreak actually occurs.

Key words: Systems thinking; accident analysis; Pennington Report; Accimap; Food Safety Culture; Human factors

\section{Highlights}

- In the past, food related outbreaks were almost always looked at from a microbiological point of view and were dealt with by trying to prevent pathogenic microbes from contaminating food.

- This study suggests that food manufacturing industries are complex sociotechnical systems and outbreaks are caused due to various human factors across various systemic levels and in order to prevent future outbreaks the issues across the various systemic levels must be addressed. 


\section{Introduction - food safety and infection outbreaks}

Poor understanding of the importance of food safety and hygiene has in the past contributed to a number of food poisoning outbreaks and at times, deaths (e.g. 1996 E.coli O157 Outbreak in Scotland, 2005 E.coli 0157 Outbreak in Wales and the Walkerton E.coli Outbreak in Canada in 2000). Reports and studies carried out on these outbreaks identified a wide range of factors contributing to these accidents. Chief amongst these were the relaxed attitudes towards food safety, lack of adequate training provision and many other such human factors related errors. The 1996 and 2005 E.coli 0157 outbreaks in the UK for example, are often seen as indicative of poor regard for hygiene and safety standards amongst food business operators (Royal Society for Public Health, 2013). The 1996 Outbreak resulted in 496 cases of E.coli 0157 infection and 18 deaths, whilst the 2005 Outbreak resulted in 1 death and 157 cases. The 2009 Godstone Farm E.coli 0157 outbreak is seen as a substantial failure of health protection and the flaws of a complex regulatory structure were identified as a major contributing factor (Griffin et al., 2010). This outbreak resulted in 93 cases, most of whom were children. 
Between 1986 and 1996, Bovine Spongiform Encephalopathy (BSE) entered the human and animal food supply despite the best efforts of regulators (Cassano-Piché et al., 2006). BSE causes a fatal disease in humans called variant Creutzfeldt-Jacob Disease (vCJD). Although 160,000 cows were slaughtered between 1986 and 1996 due to the risks of BSE, it claimed the lives of 150 people and more than 3 million cows in the UK as of 2006 (Ansell and Vogel, 2006; Cassano-Piché et al., 2006). According to Cassano-Piche et al. (2009), apart from the tragic loss of human and animal lives, it also had massive economic consequences. The association of VCJD with BSE led to loss of exports and reduced domestic demand for British beef within twelve months which amounted to a total loss of $£ 1.15$ billion. This case illustrates the dilemmas involved between science and regulation, market promotion and consumer protection, public authority and public opinion and resulted in a public policy public relations fiasco. The BSE case highlighted the failures of the then Ministry of Agriculture, Fisheries and Food (MAFF) (Ansell and Vogel, 2006), which since 2002 has been merged into the Department for Environment, Food and Rural Affairs (DEFRA). Finally, the Walkerton E.coli Outbreak in Canada (May, 2000) is another example of food poisoning due to water contamination which led to seven deaths and 2300 illnesses. Despite the authorities' efforts in developing control measures and regulations, food safety remains a complex public health issue (Faour-Klingbeil et al., 2015). Factors such as faulty inspections, poor management of facilities, falsified records and inadequate staff training led to production of contaminated food. All of these factors have been implicated in outbreak inquiries. Outbreaks are "not simply an anomalous event limited to one point in time and place, but the emergent product of an extended set of processes that evolved over time and through different scales of involvement at the political-economic, social and biophysical levels" (Ali, 2004).

\subsection{Food safety - a systems approach}

A range of factors and stakeholders play a role in providing food which is safe for consumption. These include regulators, transportation, the appropriate use of chemicals and pesticides, microbial growth conditions, food safety management systems in food businesses and storage conditions in supermarkets and stores. In his book "When Food Kills: BSE, E.coli and disaster science" (2003), Hugh Pennington suggested that it was important to take the human factor aspect into 
account while analysing outbreaks. He uses the concept of a systems based approach in this book to analyse and compare food poisoning outbreaks to the Piper Alpha, Chernobyl and the railway accidents in Ireland and Britain. A similar emphasis on the need for food science to go beyond the microbiological approach and look at the human factors involved in the accidents has also been pointed out by Griffith et al. (2010). According to Clayton and Griffith (2008) a number of studies indicate that although disregard for hygiene practices is sometimes due to negligence by the individual, it is often related to the prevailing organisational culture (Griffith et al., 2010) within the food industry. In this case it is important to realize the importance of trust (Burns et al., 2006) between the individual (workers, customers) and the organization (Schlosser, 2001) as this will influence safety in food production areas.

The sequences of events which led to the outbreaks reveal a complex interaction among the levels in a complex socio-technical system, which included the work environment, staff, management, company, regulators and government (Pennington et al., 2009; The Pennington Group, 1997; Vicente and Christoffersen, 2006). Apart from the lack of "vertical interaction" (Kirlik, 2011) Pennington also pointed out that misunderstandings and lack of communication between people are a recurrent theme in the incubation periods of disasters (Piper Alpha, Croydon Well and the 1996 E.coli O157 outbreak). A combination of the volatility of the economic climate as well as lack of regard for hygiene practices, accurate documentation and reporting led to these events; in short, there were flaws in the entire socio-technical system. Similarly, non-compliance with food safety management requirements has also been shown to be problematic. In his book "Fast Food Nation" (2001), Eric Schlosser highlights the amount of pressure put on meat industry workers; he states that there are hundreds of workers, pressed together, constantly moving and slicing, afraid of falling behind. The abattoir he visited was so cramped up and hectic that women workers were sweating although it was air conditioned. Such conditions lead to injuries to workers and injured workers impact the business due to economic consequences; hence these workers are unsubtly asked to quit by giving them the most unpleasant tasks in the slaughterhouse (Schlosser, 2011). This kind of organisational behaviour and culture leads to a negative culture in a food business.

A negligent organisational safety culture also affects the behaviour of people from the top right down to temporary staff (Royal Society for Public Health, 2013). The 
concept of organisational safety culture though largely unexplored in the food industry, is well established within other industries such as nuclear, aviation, oil and gas, rail transportation and healthcare (Antonsen, 2009; Cheyne and Cox, 2000; Griffith et al., 2010, Waterson, 2014). The 2009 report recommends that food businesses must be able to ensure food safety at all levels in their operation by making sure that the importance of food safety management is embedded in their working culture and practice (Pennington et al., 2009).

\subsection{Regulation and inspection of the Food industry in the UK}

Prior to discussing the outbreaks in detail, it is important to understand how an ideal food business is required to operate as per Food Standards Agency. Table 1 highlights the key functions of Environmental Health Officers in the UK.

Table 1 about here

The Food Standards Agency has provided a detailed guidance to people who wish to operate a food business. The main areas a food business proprietor should focus on are (1) good food hygiene, (2) following the hygiene rules, (3) having a welldocumented system in place such as Hazard Analysis and Critical Control Points (HACCP) and (4) providing training to all employees. Good food hygiene includes the so-called four Cs: cross contamination, cooking, chilling and cleaning. It is the duty of the food business to ensure that there is no cross-contamination, especially the food industries that handle meat (cooked and raw) as these are high risk industries. Adequate amount of cooking and/or chilling of food must be provided for by the business in order to prevent growth of microorganisms. Cleaning of the premises as well as the equipment used must be carried out regularly. The FSA has also made it mandatory for food businesses to use disinfectants that meet the British European (BS EN) standards. Either one of BS EN 1276 or BS EN 13697 must be present on the disinfectants. Staff training includes HACCP, instruction/training in food hygiene as well as general hygiene training such as techniques for effective hand washing. If the food business intends to sell alcohol, hot food and drink late at night or food on the street, it must acquire a license. 
Food inspectors are environmental health officers from the local authority. The main purposes of their inspections are to make sure that the food is safe to eat and that the descriptions (labels) are not misleading. The inspectors inspect the premises, foods prepared, method of working and the food safety management system. They make sure that the business complies with the regulations. During the inspection visits, they follow the Food Standards Agency's Framework Agreement on local authority food enforcement and the Food Law Code of Practice. The Feed and Food Law Codes provides the enforcers flexibility over how to deliver official food controls. It is the duty of the inspectors to provide feedback on an inspection and advice on how identified problems could be avoided. They also have to specify whether the advised action is needed in order to comply with the law or whether it is good practice. The inspectors also have the authority to inspect records, take samples and photographs of food, write informally in order to put right any problems (if they are not major risks), detain or seize suspected foods or serve notices. Notices are of three types: (1) hygiene improvement notice, (2) hygiene emergency prohibition notice and (3) remedial action notice. The first one sets out actions that must be taken to comply with the law; the second one forbids the use of certain processes, premises or equipment but must be confirmed by a court, while the third one forbids the use of processes, premises or equipment, or imposes conditions on how a process is carried out, however it does not need to be confirmed by a court. Failure to comply with any of these notices is a criminal offence. In the event of a serious case inspectors can also recommend prosecution (Food Standards Agency, 2015; Hutter and Amodu, 2008).

However, according to Ansell and Vogel (2006), the European food safety regulations have a considerable amount of flaws. Although food safety is an important and a highly salient regulatory arena, it has been brought into sharp relief in contemporary Europe. European consumers are sensitive to food safety policies due to a series of food-related scares and disputes such as mad cow disease, dioxin contamination, beef hormones, Genetically Modified Organisms (GMOs) and the recent horse meat scandal. These changes in policy coincide with two major institutional changes: (1) European integration and (2) international trade liberalization. Multi-level regulations, core disputes about risk assessment and regulatory science and the shifting balance between public and private regulation are 
among a list of various topics in which flaws in the European food policy might be said to be evident.

\subsection{Study aims and objectives}

The overall aim of the paper is to analyse the E.coli O157 outbreaks of 1996 and 2005, and explore further the role played by human factors in contributing to these accidents. In order to achieve this, the study has three main objectives:

1. To apply a systems approach to the 1996 and 2005 outbreak reports and use the Accimap method of systems analysis to analyse human and organisational issues involved in the outbreaks;

2. To reflect on the similarities and differences in terms of human and organisational factors that led up to these outbreaks and shed further light on countermeasures and ways forward to improve food and organisational safety culture in food businesses.

\section{Methods of study}

The Accimap approach was used to analyse both outbreaks. This involved the construction of a multi-layered graphical representation in which the causes of the accidents were arranged according to their causal remoteness from the outcome (Branford et al., 2009).

\subsection{The Accimap method}

Accimaps adopt a control theory-based systems approach to accident analysis and were first developed by Rasmussen (1997) and Svedung and Rasmussen (2002). Accidents are the result of unexpected, uncontrolled relationships between a system's constituent parts where the systems are analysed as whole entities instead of considering them as various parts in isolation (Underwood and Waterson, 2014). The dynamic nature of socio-technical systems means that an accident is likely to develop over time by the normal efforts of various individuals in a system and a normal variation in somebody's behaviour. This variation in behaviour can 'release' an accident (Rasmussen, 1997). 
The Accimap is a graph that represents a particular accident scenario (Svedung and Rasmussen, 2002). It represents the causal flow of events at various systemic levels such as management, regulating bodies and individual/physical processes. It was developed as a means of analysing the series of events and decision making processes which would have occurred throughout the socio-technical system and resulted in a loss of control (Branford et al., 2009). Rasmussen emphasized that all work situations leave many degrees of freedom to the actors in a system. They have the ability to choose the means and times of action even when there is a set of instructions or a set of standard operating procedures in place to follow (Rasmussen, 1997). Industries have rules and protocols in place for every task in order to achieve maximum efficiency; however failure to realize that several inter-related tasks occur at the same time often leads to accidents. Rules, laws and instructions are never followed to the letter. The Accimap model depicts the control of socio-technical systems over six basic organisational levels:

- Government level: Laws and legislation developed to control the hazardous procedures

- Regulatory bodies and associations: Where the legislation is converted into industry rules and regulations

- Company level: Where the rules and regulations are integrated into the company rules and policies

- Management level: Where the staff activities and roles are specified and overseen with reference to the company level rules and policies

- Staff level: The work force that follows the rules set about by their managers.

- Equipment and surroundings: Where the company's rules and policies apply based on the government level regulations

Figure 1 about here

The Accimap has been used to analyse individual accidents such as the Überlingen mid-air collision (Branford, 2011), the railway crash at Kerang (Salmon et al., 2013) and the Black Hawk Friendly Fire Shoot Down (Harvey and Stanton, 2014) 
and is used as a guide or template to help organize the research endeavour in a systematic fashion. Safety not only depends on the individuals who interact with hazardous processes on a daily basis, but also on the activities of individuals at every level in the system and the quality of interaction between these levels. This is the basis of the Accimap approach which due to its graphical representation helps identify the causal factors behind an accident and the events that led to it. Due to external influences such as political, financial and technological factors, the levels are not stable and change constantly in order to adapt. Maintaining control is hence a dynamic process, involving the entire socio-technical system (Svedung \& Rasmussen, 2002).

\subsection{Procedure for analysing the outbreak reports}

The Accimap analyses of the outbreaks were performed by the first author. The analyses were then reviewed by the second author. While both individuals are human factors researchers, the first researcher has experience in food safety and food science and the second researcher has experience in applying human factors and accident analysis methods in various domains (e.g. rail, construction, aviation and healthcare). Upon completion of the analyses, the researchers exchanged and reviewed the outputs and any disagreements were resolved through discussion until consensus was reached in a similar manner to the approach described in Underwood and Waterson (2014).

Branford, Naikar and Hopkins developed (2009) a standardised Accimap approach which involves a set of guidelines that incorporate factors common to all the varieties of Accimap approaches. This format incorporates a set of guidelines for identifying the causal factors and illustrates how the causes led to the outcome. It also helps to promote the development of safety recommendations and can be used in multiple fields to analyse organisational accidents in a complex socio-technical system. A number of steps described by Branford et al. (2009) were followed for the analysis of each accident. A few changes were made to the types of factors in the Accimap diagrams. These are described in the form of direct, indirect and complex causes, pre-conditions and outcomes. Critical events, which if avoided, would have completely prevented the following outcome are categorized as "direct causes". 
Indirect causes are those causes which did not have a straightforward role to play in the next outcome. These are the causes which even if prevented, could not prevent the outcome, as there were other factors that also led to the same outcome.

Preconditions are those events which either lead to a direct or an indirect cause, but are not causes themselves. The 'complex cause' concept is a novel concept as it indicates that a cause is direct as well as indirect and that it had multiple roles to play in the outbreak.

Table 2 about here

The Pennington reports on the 1997 and 2005 outbreaks were reviewed in detail, independently by both the authors and analyses of the following steps were carried out: (1) construction of a timeline of the events involved in the outbreaks; (2) contributory factors that led to the outbreak; (3) which of these were human factors; (4) systemic level in which the human factor was present. Table 2 describes in detail the coding used to construct the Accimap. The resulting Accimaps are presented in Figures 2 and 3, Tables 5 and 6 and discussed in detail in Section 5.

\section{The Outbreaks}

\subsection{Events proximal to the 1996 E.coli O157 Outbreak}

The Public Health Department of Lanarkshire ('the Health Board') identified the possibility of a food poisoning outbreak caused by infection with E.coli O157 on $22^{\text {nd }}$ November 1996 after they became aware of the many cases of infection in residents of Wishaw in the central belt of Scotland. On the same day, the Board notified the Environmental Services Department of North Lanarkshire Council ('the Council) and arrangements were made to investigate and control the outbreak in accordance with the updated guidelines issued in 1996 by The Scottish Office Department of Health Advisory Group on Infection. On $23^{\text {rd }}$ November 1996, an Outbreak Control Team (OCT) was formed.

Histories obtained from 9 out of the 15 cases by the evening of $22^{\text {nd }}$ November 1996 indicated that 8 out of 9 had consumed food obtained either directly from $\mathrm{J}$. 
Barr and Son butchers or at a church lunch which was served by the same butchers. Although it looked like a small butchers shop from the outside with a bakery attached, J. Barr and Son was involved in the production and distribution of raw and cooked meats and bakery products from the Wishaw premises and employed 40 people, most on a part-time basis. Mr Barr was visited by representatives of the Health Board and the Council on $22^{\text {nd }}$ November 1996 and the entire business was closed voluntarily on $27^{\text {th }}$ November 1996. Many factors led to the outbreak such as the absence of a documented system in order to keep note of all the outlets they supplied meat to and exemption from Meat Products Regulations 1994.

The Outbreak Control Team's first meeting was on $23^{\text {rd }}$ November 1996. Initially they met every day; however the frequency was reduced later on as the Outbreak was brought under control. The Scottish Office Department of Health (SODoH) and the Agriculture, Environment and Fisheries Department (SOAEFD) met with the Health Board and the Council on $26^{\text {th }}$ November 1996 and a Food Hazard Warning was issued by the Scottish Office on the $27^{\text {th }}$. Further detailed guidance and advice was issued in the form of a further Food Hazard Warning on the $28^{\text {th }}$ of November. On the same day, the Scottish Office attended the OCT meeting as observers and the Secretary of State for Scotland announced in Parliament the establishment of an Expert Group to examine the circumstances which led to the outbreak in the central belt of Scotland and to advice on the implications for food safety and the general lessons to be learned. This group was to be chaired by Professor Hugh Pennington. The OCT dealt with a range of matters mentioned in the guidelines and a few specific issues arose out of this. This helped the Group realized that the guidelines needed a reviewing too as there could be faults in them. The identification, management and control of the outbreak was managed very well due to enormous efforts, the ability to make difficult professional judgements and the availability of only a limited amount of resources.

After the outset of the outbreak the number of cases increased dramatically. It began as one probable case on November 9, 1996 and went as high as around 23 confirmed and 16 possible cases on November 25, 1996. This was due to the fact that Barr distributed his products into the whole central belt of Scotland. Hence there were also cases from the Forth Valley, Lothian and Greater Glasgow. Due to the absence of a documented system to keep track of the places Barr distributed his 
food products to, the OCT couldn't assume that there was only one source of contaminated food. Both, epidemiological and microbial evidence show that the outbreak consisted of several separate but related cases (as shown in Table 3). The final date for the onset of illness was $15^{\text {th }}$ December 1996 and the outbreak was declared as over on $20^{\text {th }}$ January 1997 , however the possibility of further cases due to secondary spread was recognized. Further deaths due to prolonged illness were also recognized. This is the largest ever outbreak of infection caused by E.coli $\mathrm{O} 157$ in UK.

The scale of the outbreak placed the local health resources under substantial pressures. The Wishaw clinic in Lanarkshire carried out batches of tests on some 969 people with diarrhoea, in addition to the number of people who attended their GP. 127 people were admitted to the hospital, out of which, 13 required dialysis on a daily basis. All these 13 people were transferred to Glasgow. 27 people were diagnosed with having haemolytic uremic syndrome. There were 18 deaths (all adults) due to the outbreak, which was the second highest number of deaths associated with an outbreak of E.coli 0157 infection in the world at the time of writing the report. Of these 18, 8 had attended the luncheon served at Wishaw Old Parish Church on $17^{\text {th }}$ November 1996 and 6 were residents of Bankview Nursing Home in Bonnybridge, Forth Valley. In Lanarkshire, the 12 people who died were of the ages between 69 and 90 years and in the Forth Valley, the range was between 70 and 93 years.

Table 3 about here

\subsection{Events proximal to the 2005 E.coli 0157 outbreak}

The September 2005 E.coli 0157 outbreak in South Wales was the largest outbreak caused by a single microorganism in Wales, and the second largest in the UK. A total of 157 cases were identified, of which 118 were confirmed microbiologically as E.coli O157. 109 of these 118 were of a strain unique to the Outbreak. Children from 44 schools across four local authorities were infected; thirty one people were admitted to hospital and one died. The objectives of the inquiry were to investigate the circumstances that led up to the Outbreak of E.coli $\mathrm{O} 157$ 
infection in South Wales on September 2005 and into the handling of the Outbreak. Substantial amounts of oral and written evidence were collected.

Cooked meats contaminated with E.coli $\mathrm{O} 157$ were identified as the main cause of the Outbreak. Microbiological testing proved that the strains of E.coli O157 obtained from people infected were the same as those found on the cooked meats recovered from schools, in a sample of raw meat obtained from John Tudor \& Son and in samples of cattle faeces taken from the farm ('the Farm'). Cattle from the farm were slaughtered at J.E. Tudor \& Sons Ltd, an abattoir owned by Tudor. The abattoir supplied meat to John Tudor \& Son. Food hygiene failures, repeated breaches of the Food Safety Regulations, falsified records and an invalid Hazard Analysis and Critical Control Points (HACCP) plan at the premises of John Tudor \& Son led to the Outbreak; hence the responsibility fell on the shoulders of William Tudor, the Proprietor. He misled the Environmental Health Officers on issues such as the use of the 'vac packing machine', for example, he claimed that it was away for repair. Deficiencies in food safety practices existed for a long time prior to the Outbreak.

The inspections undertaken by the Environmental Health Officers (EHOs) from the Bridgend County Borough Council were made less effective due to William Tudor's dishonesty. The inspections failed to monitor the business's management of food safety. Important clues were missed and those that we identified were lost in the system as there was no method of alerting other Environmental Health Officers to the issues (this was important as there were frequent changes in the environmental health officers who visited the sites). Failures in the HACCP plan were very important and should have been picked up on. The Bridgend County Borough Council was last audited by the FSA in February 2004. The draft of the final report was not provided to the council until $17^{\text {th }}$ June 2005 , although a feedback was given at the end of the audit. Since the audit was system-based, it did not evaluate the quality of the inspections, but only whether or not there were systems in place to check methods.

John Tudor \& Son supplied the schools under contract with Rhondda Cynof Taf, Bridgend, Caerphilly and Merthyr Tydfil County Borough Councils. The process by which these contracts were awarded in 1998 and 2002 contained major flaws. The details in the contract, roles and responsibilities between the organisations and key individuals, were not clear. Neither was the contracts monitored properly nor were 
complaints properly recorded. A threat to securing a contract would have motivated John Tudor \& Son to maintain good food safety practices.

Since the J.E. Tudor and Sons abattoir neither enforced nor followed the Meat Hygiene Regulations, contamination of the meat products manufactured by them was inevitable. The Meat Hygiene Service also failed to carry out its duties properly as the abattoir was allowed to function despite a continuous breach of the legislative requirements. A 'light touch' (Pennington et al., 2009, p.14) approach was adopted; this meant that businesses were not closed down in order to promote the meat industry. The reason for adopting this approach was to promote the meat industry in the UK. This might be construed as a flaw and a bias in food safety policy in the European Union (Ansell and Vogel, 2006). This proved to be too costly especially with regard to the Tudor \& Son business. Although the hygiene problems at the abattoir were picked up on, they were allowed to carry on functioning without the need for significant improvements. This caused a substantial increase in the risk of E.coli 0157 contaminated meat coming out of the abattoir, which caused an increase in the risk of unsafe food being produced and supplied into the food chain. This led to the Outbreak.

The OCT identified the common link between the cases at a very early stage and then reacted quickly to remove the cooked meats from the food chain. The efficiency of their work helped limit the spread of the Outbreak. They put in considerable time and effort to tackle the Outbreak, and also put in extra hours and out-of-hours working. In-patient hospital care was as effective as could be. At the earlier stages, there were some communication difficulties as there was no robust system for contacting Local Health Boards out-of-hours. However this did not have any adverse effects with regard to the outbreak control. This outbreak exposed the weaknesses in communication on a serious public health issue, which does not just limit to this E.coli 0157 case. The only two systems that worked well were Treatment and Care and Outbreak Control.

W. Tudor and Sons disregarded food safety and the health of all the people who consumed meat products produced and distributed by his business. He pleaded guilty to seven offenses and was sentenced to twelve months imprisonment and banned from managing food business in the future. 
Table 4 about here

\section{Findings}

\subsection{E.coli O157 Outbreak analysis}

The Accimap diagram resulting from the analysis is presented in Figure 2. The proximal events leading up to the outbreak are described in Table 3. These events, e.g. the charging of Mr John Barr with culpable and reckless conduct arising from the alleged supply of cooked meats on $10^{\text {th }}$ January 1997 , acted as reference points to begin analysis at the workplace system level as well as the physical/individual events and conditions level.

Although the Outbreak was labelled as an E.coli O157 outbreak, the systems analysis carried out showed that an accumulation of various other precursor factors led to the food poisoning outbreak in 1996. These causal factors were included in the analysis diagram under to show the gradual deterioration and failures at various levels throughout the system. These factors were also assimilated in order to analyse the individual factors, factors within a system and interactions between factors throughout the whole system.

The focus of the diagram was on two important factors: (1) lack of adequate regulations and (2) lack of regard for food hygiene by the business. It reveals the fact that the outbreak was not caused by individual errors at levels 4 or 5 , but attributable to an accumulation of major factors right from level 2 such as lack of adequate resources for Environmental Health Officers and legislation for butchers' shops. Five direct causes, two indirect causes and two pre-conditions were identified in level 2 of the analysis. The number of causes at level 2 (government level) are lesser than the number of causes in level 3 (organisational/workplace level). However, most of the causes in levels 3 and 4 , and a lot of the final outcomes in level 5 arose due to the causes in level 2.

At the government level, most of the factors were related to inadequate regulations such as presence of loopholes in the Codes of Recommended Practices and Guidance, no mandatory requirement for food businesses to have a HACCP based system in place and the absence of legal authority to Meat Hygiene Services over transportation to non-registered premises. Factors related to the Environmental 
Health Officers included inadequate number of EHOs, high work pressure, lack of adequate resources, EHOs being involved in other areas such a regulating noise and air pollution and few food safety trained managers. These factors led to a lack of motivation and poor morale in the Environmental Health Officers (EHOs). Only a few factors had a role to play at the external level. These included inadequate media awareness and commercial pressures. As it was expensive to carry out regular media awareness campaigns, this form of communication was seldom used. Commercial pressures were in the form of high demand from consumers and business owners. As this business distributed to a large number of consumers, $\mathrm{Mr}$ John Barr pressurised the environmental health officers to approve of the systems in place.

A large number of factors led to the E.coli 0157 outbreak. The factors that were directly linked to the outbreak were mostly either due to human errors at the workplace level, or individual and physical events and conditions. The analysis highlighted the importance of regulations for butchers' shops as without these, the businesses took advantage of the absence of regulatory measures and disregarded hygiene practices and food safety protocols. According to the European Union (EU) food law in 1996, a food business was responsible for ensuring the safety and protection of the consumer. The EU food hygiene legislation also required food businesses to undertake "own checks" (The Pennington Group, 1997) based on some of the Hazard Analysis and Critical Control Point (HACCP) principles; however, implementation of all the HACCP principles was not a legal requirement. The inconsistency in requirements among the vertical (product specific regulations that deal with requirements for dealing with the product throughout the production process) and horizontal (covers a wide range of premises) regulations combined with the inadequate regulations led to confusion within the food business. Absence of a documented system was the major problem at the organisational and workplace level. Due to this, the distribution chain could not be traced and possible hazards were not analysed. External factors such as commercial pressures put the OVSs under pressure to lower their evaluation standards and pass unhygienic cattle for slaughter. Since E.coli 0157 does not show symptoms in animals, it added in extra complexity as it could neither be tackled at the government level, nor at the workplace level and hence is shared between both. Other factors at the workplace 
level included food being prepared at non-registered premises such as church halls and community centres and expenses to carry out microbiological testing. At the physical and individual events level, factors such as faulty layout and design of the plant, poorly planned equipment design, no separation of raw and cooked meats, presence of untrained helpers at the church hall and community centre events and faulty temperature monitoring and controlling systems played an important role in the 1996 E.coli O157 Outbreak. The causes in level 4, similar to level 3, were mainly due to lack of adequate regulations and led to the outcomes in level 5 . Level 5 in the diagram shows all the outcomes which were caused either directly or indirectly by the factors in the other levels.

Figure 2 and Table 5 about here

\subsection{E.coli O157 Outbreak analysis}

The Accimap diagram resulting from the analysis is presented in Figure 3. The proximal events leading up to the outbreak are described in Table 4. These events, e.g. the death of Mason Jones due to infection caused by E.coliO157 on $4^{\text {th }}$ October 2005, acted as reference points to begin analysis at the workplace system level as well as the physical/individual events and conditions level.

Similar to the1996 Outbreak this outbreak too was labelled as an E.coli O157 outbreak. However the systems analysis carried out showed that an accumulation of various other precursor factors led to the food poisoning outbreak in 2005 . The Accimap highlights the interactions between factors both, within and between the four levels, which led to the outbreak in 2005. These factors were also assimilated in order to analyse the individual factors, factors within a system and interactions between factors throughout the whole system.

The focus of the diagram was on two important factors: (1) faults in the government's approach and (2) lack of regard for food hygiene regulations by the business. From Figure 3, it can be seen that all the factors across the various levels are interconnected in a complex manner. At the government level, although detailed regulations were present, factors such as faulty auditing, lowering of the annual budget, the 'light touch' approach (Pennington et al., 2009, p.14) and inadequate 
services provided to the council were events that led to the outbreak. Most of the factors at the local council level were outcomes of the factors in level 1. Faults such as environmental health officers not being adequately trained in HACCP, lack of communication with employees, reduction in the number of EHOs, use of consultants and overdue inspections highlight the fact that at the local council level, all the factors were related to the Environmental Health Officers in some way or another.

Level 3 (organisational/workplace level) is divided into two sections: (1) management and (2) cleaning/premises in order to clearly define the factors. The management section comprises of all the errors made by the management at Tudor \& Sons. The aim of this section is to highlight the disregard for food hygiene regulations by the management team at Tudor \& Sons. This is the maximum number of causes when compared across all the levels indicating that the maximum number of human errors that led to this outbreak were at the management level. The latter section comprises of errors made with regard to cleaning of equipment and clothing at the workplace level. In this sub-level, lack of supervision by the management led to lack of regard for hygiene practices, which in-turn led to most of the other factors such as use of wrong soaps for cleaning, not washing their boots and clothes regularly, absence of a cleaning protocol and inadequate cleaning equipment. This factor was the consequence of errors made by the Environmental Health Officers at the local council level. This single link is an example of the interconnected nature of this outbreak. Level 4 highlights the physical and individual errors such as no regard for personal hygiene and no change of clothes while moving between the raw and cooked meat areas of the factory. Similar to section 4.1, Level 5 in the diagram shows all the outcomes which were caused either directly or indirectly by the factors in the other levels.

Figure 3 and Table 6 about here 


\section{Discussion - comparing the outbreaks}

In order to compare the two outbreaks, we focus in this section on contributory factors which were 'external' to the outbreak ('macro factors - e.g., related to regulation and government of food safety) and 'internal factors' ('micro' factors - e.g., organisational and workplace levels of analysis). A final section examines some of the interactions between these external (macro) and internal (micro levels of analysis).

5.1 External factors ('macro'): regulation and government of food safety

As seen from Figure 4, at the government/local council level the common factors were (1) complacency in food safety (2) inadequate support provided to EHOs and (3) provincial budget cuts. Examples of complacency in food safetyinclude (a) absence of implementation of Hazard Analysis and Critical Control Point (HACCP) in the 1996 Outbreak (as a consequence of this, industries did not have any documented system in place whereby their processing methods, hygiene standards and supply chains could be traced), (b) loopholes in the Codes of Recommended Practices and Guidance which allowed exemption from 1994 Regulations (food industries had the ability to find a way around the need to maintain hygiene standards. In the 2005 Outbreak, the Tudor business was not inspected before awarding them a contract to serve schools), (c) faulty audits, (d) use of a 'light touch' approach (the abattoir was allowed to function despite clear breach of regulations) and (e) authorities not having a defined role highlight the slapdash approach adopted at the government level.

Provincial budget cuts meant reduced budgets for Environmental Health Officers indicating that this department was not considered to be as important as other branches in the local council. As a result of reduced funding, the department could hire only a limited number of environmental health officers. This added to the work load on the EHOs who were already dealing with environment and housing safety as well as food safety issues. Similarly, HACCP training could not be provided to all the senior managers. As quite a few of the senior managers were not trained in HACCP, they had no clue about HACCP and its importance and hence were not competent enough to deal with food safety related matters. In the 1996 Outbreak, the 1995 Regulations that were in place were too complicated and were not as prescriptive; 
this led to widespread confusion at the workplace level. This, in combination with the presence of loopholes such as Codes of Recommended Practices and Guidance led to the rise of other factors at the organisational/workplace level. Risks that can arise during transport had been underestimated at the local council level. The fact that there was no legal requirement to implement the directives and the presence of mixed transportation standards gave the food business a free hand in the transport conditions. This demonstrates that until the 1996 Outbreak occurred, the government underestimated the importance of a detailed regulation. These flaws were rectified as per the recommendations by The Pennington Group Report (1997).

\subsection{Internal ('Micro') factors: organisational and workplace levels of analysis}

In both the outbreaks, meat, which is a high risk food with regard to the number of microorganisms in it (Al-holy and Rasco, 2015; Paik, Lee et al., 2014; Xiong et al., 2015) was served to highly vulnerable populations; to the elderly population in the 1996 Outbreak and school children in the 2005 Outbreak without proper processing (Pennington et al., 2009; The Pennington Group, 1997). The vulnerability of the population determined the scale of the outbreak as the chances of being affected by pathogens was higher due to weaker immunity. Unlike the comparison between Walkerton and North Battleford cases by Woo and Vicente (2003), there are both common as well as unique factors between the outbreaks in Scotland and South Wales. Figure 4 illustrates the common factors between both the outbreaks. At the organisational/workplace level compliancy failures was the common causal factor. There was neither any proper documented system in place nor any regard for hygiene and food safety. Although in 1996 there was no regulation making it mandatory to have a HACCP based system in place, there were legal requirements to conduct a hazard analysis. Blatant disregard for hygiene and food safety was a common factor in both the food businesses. Due to Tudor's intimidating nature (2005 Outbreak) and a reduction in number of EHOs the Official Veterinary Surgeons (OVSs) were under pressure to approve all the cattle they had to evaluate. It is highly likely that under pressure the OVSs could have also made additional unintentional mistakes. Due to this pressure, the OVSs also did not have a consistent approach while carrying out their evaluations. 
From a system designer's point of view, some of the factors across the systemic levels are very difficult to anticipate while designing equipment or buildings to protect public health. The nature of these factors makes it difficult to identify a systematic approach to the management of risk in complex socio-technical systems (Woo and Vicente, 2003). In order to do so one would have to undertake a comprehensive study of the culture in food businesses to identify various possible issues (similar and unique). Although the basic outline for safety and hygiene is the same, due to cultural differences the business culture would vary from country to country. For example, the food business operational culture in the UK would be different from that in Saudi Arabia. If the targets are variable, how can there be an orderly remedy? (Woo and Vicente, 2003).

As Figure 4 in this study contradicts Figure 6 in the study carried out by Woo and Vicente (2003), it would be inaccurate to conclude that common factors tend to be present at higher systemic levels. However by comparing various accidents across multiple sectors (nuclear, gas, rail and hospital) and within the same sector (food), it would be unerring to point out that there are factors which are specific to certain systemic levels. Figure 4 also highlights a range of factors across various systemic levels that led to similar outbreaks even after nine years. On comparing Figures 2, 3 and 4 , it can be seen that although there were few unique causal factors related to each outbreak, when looked at on the whole most of the factors that led to the 1996 and 2005 outbreaks were similar (for e.g. cross contamination, lack of training, erroneous approach by food business operators and food businesses). As compliancy failures were a common factor in both the Outbreaks, an approach must be designed such that it addresses complacency and compliancy failures across every level in the food industry. In 2003, Woo and Vicente compared the work done by Hrudey et al. and Rasmussen's framework and deduced that the only way to address these systemic failures would be by identifying the possible threats at each level and finding possible solutions.

5.3 Interactions between internal ('macro') and external ('micro') levels of analysis 
In both the cases there was interaction between complex human beings, complex organisations and complex machines (Sagan, 1995). Conflicting interests is one of the common causal factors across both the accidents. Complex organisations find it hard to manage hazardous technologies and processes due to the inevitable presence of conflicting priorities (Sagan, 1995). As both Barr and Tudor prioritized maximum production and profits over hygiene and food safety, even employees who wanted to ensure good manufacturing practices were not able to do so due to conflicting interests and hierarchy; ambiguous preferences led to a state of uneasy tension. According to Sagan (1995), safety is reduced when leaders themselves do not have strong incentives to improve safety. In both the 1996 and the 2005 outbreaks, carelessness was a common micro as well as macro factor. Environmental Health Officers failed to report or detect faulty activities at either of the businesses; due to budget cuts, the number of EHOs was also reduced greatly and there were frequent changes in managers. This led to confusion while checking records. At the organisational level, carelessness was rampant among management as well as staff working on the floor. Repeatedly ignoring hygiene practices in order to maximise profits and intimidating employees played a major role in leading to these outbreaks.

Constraints on learning was another common causal factor in both the outbreaks. In his book "The Limits of Safety" (1995), Sagan states that political factors are usually the root of most other causal factors. Organisations do not have simple, consistent preferences; instead they exhibit internal conflict over preferences. These conflicts lead to a shift from problem solving to the rise of political factors. Factors such as strong disincentives against reporting or noting failures existed in both the businesses. This influenced the reporting of near-misses by workers, stress-levels and the belief of what is acceptable to record, which in-turn affected the interpretation of events by the authorities. Unofficially there were two sets of behaviours in the businesses, "back-stage behaviour" and "front-stage behaviour". Front-stage behaviour includes inaccurate records of behaviours and actions; these were actions that should have ideally been carried out in a food business. Backstage behaviour consists of the actual behaviours and actions that were carried out in both the businesses (e.g. attitudes of the food businesses operators towards food safety and hygiene, deviation from regulations, etc.). 
All businesses have powerful individuals inside the organisations who try to manipulate behaviour and change the business' goals. Both Tudor as well as Barr manipulated hygiene practices and forced the workers to manipulate records; however Sagan (1995) also states that as things are never as they seem, the managers or workers should not ignore a near-miss accident only because they have been told to do so. In both the 1996 as well as the 2005 outbreaks, the managers and workers also ignored hygiene practices only because they were told to do so. Food businesses are complex organisational systems that manage hazardous technologies; serious accidents in such systems are inevitable according to the normal accidents theory (Sagan, 1995). As organisations are "natural open systems" (Sagan, 1995), they pursue their own goals such as company security and survival and mostly focus on production, reliability and generating profits. The garbage can model proposed by March, Cohen and Olsen states that complex organisations make radically different decisions compared to the ones that fall under the rational models (Sagan, 1995). From both the outbreak reports it can be seen that Tudor's as well as Barr's business had ill-defined preferences where different individuals at different levels of the organisation had different preferences. This led to confusion in the organisations as processes were not understood by its own employees. One of the main reason for this ignorance is that the organisations involved did not fathom the consequences of their actions.

Insert Figure 4 about here

\section{Conclusions, future work and study limitations}

Systemic analyses of both the outbreaks suggest that the food industry is a complex socio-technical system consisting of various systemic levels. Currently the focus within the food industry is on microbiological analyses. This will only help solve the problems at a very late stage in the food manufacturing process. In order to address food safety related issues it is important that we look at the food industry as a whole and aim to identify and solve problems that could arise at each of the systemic levels. These 'problems' usually arise during the incubation phase of a disaster - that is, the period prior to the disaster during which certain organisational 
processes and factors allow a disaster to occur; these factors accumulate unnoticed (Ali, 2004). As seen from this study, both the outbreaks had common as well as unique factors. Similarly, food poisoning outbreaks occurring in any part of the world also have common factors associated to them as seen in various other outbreaks such as the 2009 Godstone Farm E.coli O157, the Bovine Spongiform Encephalopathy case between 1986 and 1996 and the Walkerton E.coli Outbreak in Canada among many others (Cassano-Piché et al., 2006; Clayton and Griffith, 2008; Griffin et al., 2010; Griffith et al., 2010; May, 2010; Nayak and Waterson, 2015; Pennington, 2003). The study also suggests that the use of a systems approach to analyse the human and organisational issues involved in outbreaks is a practical method as it helps to identify multiple key causal factors, gain an in-depth insight into the functioning of the food industry and identify faults (if any). Normal accident theorists believe that a strong organisational culture (intense socialization, strict discipline and isolation from the problems of broader society) is needed to reduce the number of accidents; however what needs to be assessed is whether due to the strict "military model" (Sagan, 1995), achieving these targets is plausible as it is impossible to maintain strict discipline and to ensure isolation from the problems of broader society in a non-militiary organisation (Sagan, 1995).

Future research should assess whether the findings of this analysis is generalizable across a broader set of cases within the food industry sector. In order to do so it would be important to assess the safety culture in food industries as this would help better understand the vertical integration in businesses. The lesson from other industries is that safety culture is often difficult to assess. The definition of safe behaviour is a matter of interpretation; hence the extent of compliance by industries to ensure food safety and hygiene would vary as long as there is no universal protocol. The variation would depend on the organisational role and professional background (e.g. management and workers attitude towards good hygiene practices). It is important to understand the relationship between poor food safety culture, lack of motivation amongst employees and management and a poor morale amongst environmental health officers due to budget cutbacks. The effects of budget cutbacks can be seen in the report by Thompson and Garrett-Peltier (2012); they state that the Ryan budget plan, named after the principal author of the bill (Chariman Paul Ryan), which proposed a $\$ 127$ billion cut, would lead to a loss of more than 174,000 jobs in 
one year; each $\$ 1$ billion cut would eliminate 13,718 jobs. The Ryan budget plan was a Republican budget plan drawn for the 2014 elections in the United States of America. The report by Hastings et al. (2015) states that the most deprived authorities in England have a level of budget cut nearly six times higher than the cut experienced in the least deprived areas. These austerity measures have led to the authorities working with scarce resources, and this in turn has led to a strain on basic services. Applying this to the UK context and to the outbreaks analysed in this paper, the budget cutbacks in the food safety industry led to loss of jobs for a few Environmental Health Officers (EHOs) while the ones who retained their jobs were burdened with too many tasks as they had to assess the same number of businesses with reduced man-power. We note in passing that similar cuts to EHO numbers are likely to have an impact on present day food safety. Hence these three factors lead to lack of compliance and affect the safety culture in food businesses. A better understanding of the attitudes of employees and management in the food industry is needed alongside an audit of tools used to assess food hygiene and safety. It is important to understand that human-induced stresses induce effects that reverberate throughout the whole system (Ali, 2004) which lead to accidents.

A major limitation of the approach used is that in retrospect, all events that led to the outbreaks seem to be very clear; hence there is a retrospective bias in this kind of analysis. Hindsight bias, which is the tendency to exaggerate the a priory predictability of outcomes after they have become known (Fessel et al., 2009), is a major limitation for this study as predictive judgements could be distorted by knowledge of the outcomes of the events predicted. Once events have occurred they have higher postdictive than predictive probabilities; this means that once an event is reported, its perceived inevitability increases significantly (Fischhoff and Beyth, 1975). However according to Mazursky and Ofir (1990), if analyses of past events are not carried out, unexpected events are meted out by exaggerated adjustment in a direction opposite to hindsight bias. In other words, in order to explain unexpected events, people tend to "recall significantly lower expectations" (Mazursky and Ofir, 1990) and hence these forms of analyses are essential. Systems analyses of the type we have described in this paper are also needed.

Word count: 8,475 (excl. Tables and figures) 


\section{References}

Al-Holy, M. A., \& Rasco, B. A. (2015). The bactericidal activity of acidic electrolyzed oxidizing water against Escherichia coli O157:H7, Salmonella Typhimurium, and Listeria monocytogenes on raw fish, chicken and beef surfaces. Food Control, 54, pp. 317-321.

Ali, S.H. (2004), A socio-ecological autopsy of the E. coli 0157:H7 outbreak in Walkerton Ontario, Canada. Social Science and Medicine, 58: 2601-2612.

Ansell, C., \& Vogel, D. (2006). What's the beef?. London:The MIT Press. pp. 1-180.

Antonsen, S. (2009). Safety Culture Assessment: A Mission Impossible? Journal of Contingencies and Crisis Management, 17(4), pp. 242-254.

Branford, K. (2011). Seeing the Big Picture of Mishaps. Aviation Psychology and Applied Human Factors, 1(1), pp. 31-37.

Branford, K., Naikar, N., \& Hopkins, A. (2009). Guidelines for Accimap Analaysis Part A : Standardising the Accimap approach The Accimap approach. In A. Hopkins (Ed.), Learning from High Reliability Organisations (pp. 193-212).

Burns, C., Mearns, K., \& McGeorge, P. (2006). Explicit and Implicit Trust Within Safety Culture. Risk Analysis, 26(5), pp. 1139-1150.

Cassano-Piche, A., Vicente, K. J., \& Jamieson, G. A. (2006). A Socio-technical Systems Analysis of the BSE Epidemic in the UK Through Case Study. In Proceedings of the Human Factors and Ergonomics Society Annual Meeting (Vol. 50, pp. 386-390).

Cassano-Piche, A. L., Vicente, K. J., \& Jamieson, G. A. (2009). A test of Rasmussen's risk management framework in the food safety domain: BSE in the UK. Theoretical Issues in Ergonomics Science, 10(4), pp. 283-304.

Clayton, D. A, \& Griffith, C. J. (2008). Efficacy of an extended theory of planned behaviour model for predicting caterers' hand hygiene practices. International Journal of Environmental Health Research, 18(2), pp. 83-98.

Cox, S. J., \& Cheyne, a J. T. (2000). Assessing safety culture in offshore environments. Safety Science, 34, pp. 111-129. 
Faour-Klingbeil, D., Kuri, V., \& Todd, E. (2015). Investigating a link of two different types of food business management to the food safety knowledge, attitudes and practices of food handlers in Beirut, Lebanon. Food Control, 55, pp. 166-175.

Fessel, F., Epstude, K., \& Roese, N.J. (2009). Hindsight bias redefined: It's about time. Organizational Behavior and Human Decision Processes, 110, pp. 56-64.

Fischhoff, B., \& Beyth, R. (1975). "I knew it would happen" Remembered probabilities of once-future things. Organizational Behavior and Human Performance, 13, pp. 1-16.

Food Standards Agency. Food law inspections and your business. Available:

http://www.food.gov.uk/business-industry/hygieneratings/food-law-inspections. Last accessed 10th Sep 2015.

Griffin, G. (2010). Review of the major outbreak of E. coli O157 in Surrey, 2009. Retrieved from http://www.griffininvestigation.org.uk/report/full report.pdf

Griffith, C. J., Livesey, K. M., \& Clayton, D. (2010). The assessment of food safety culture. British Food Journal, 112(4), pp. 439-456.

Harvey, C., \& Stanton, N. A. (2014). Safety in System-of-Systems: Ten key challenges. Safety Science, 70, pp. 358-366.

Hastings, A., Bailey, N., Bramley, G., Gannon, M., \& Watkins, W. (2015). The Cost Of The Cuts: The Impact On Local Government And Poorer Communities. pp. 1-24.

Jenkins, D. P., Salmon, P. M., Stanton, N. A, \& Walker, G. H. (2010). A systemic approach to accident analysis: a case study of the Stockwell shooting. Ergonomics, 53(1), pp. 1-17.

Kirlik, A. (2011). Socio-technical systems, risk and error. In: Vicente, K.J. Humantech. New York: Oxford University Press. pp. 191-196.

Mazursky, D. \& Ofir, C. (1990). "I Could Never Have Expected It To Happen": The Reversal of the Hindsight Bias. Organizational Behavior and Human Decision Processes, 46, pp. 20-33.

Nayak, R., \& Waterson, P. (2015). The challenges of assessing food safety culture, The Ergonomist, June v. 540, pp. 12-13.

Paik, H., Lee, Y. J., Jung, B. S., Yoon, H. J., Kim, K., Lee, J. (2014). Predictive model for growth kinetics of Listeria monocytogenes in raw pork meat as a function of temperature. Food Control, 44, pp. 16-21.

Pennington, T. H. (1997). The Pennington Group: Report on the circumstances leading to the 1996 Outbreak of infection with E.coli O157 in Central Scotland, The Implications for food safety and the lessons to be learned. Edinburgh: HM Stationary Office. pp. 1-42. 
Pennington, T.H. (2003). When Food Kills:BSE, E.coli and disaster science. Oxford: Oxford University Press. pp. 1-240.

Pennington, T. H. (2009). The Public Inquiry into the September 2005 Outbreak of E.coli 0157 in South Wales. pp. 1-258.

Rasmussen, J. (1997). Risk management in a dynamic society: A modelling problem. Safety Science, 27(2), pp. 183-213.

Hutter, B.M. and Amodu, T. (2008) Risk regulation and compliance: Food safety in the UK' Report Commissioned by The E.coli Public Inquiry.' London: London School of Economics and Political Science. Available from:

http://www.Ise.ac.uk/accounting/CARR/pdf/ncp04219.pdf (last accessed November 13th 2015).

Salmon, P. M., Finch, C., Lenné, M. G., Goode, N., \& Grant, E. (2015). Rasmussen's (1997) Risk Management Framework. Retrieved June 11, 2015, from http://uploadsproject.org/rasmussens-1997-risk-management-framework/

Salmon, P. M., Read, G. J. M., Stanton, N. A., \& Lenné, M. G. (2013). The crash at Kerang: Investigating systemic and psychological factors leading to unintentional non-compliance at rail level crossings. Accident Analysis and Prevention, 50, pp. 1278-1288.

Schlosser, E. (2001). Fast Food Nation. London:The Penguin Press. pp. 3-224.

Stanwell-Smith, R. (2013). Just desserts from our poor food safety culture? Perspectives in Public Health, 133(6), pp. 282. Retrieved from http://www.ncbi.nlm.nih.gov/pubmed/24214999

Svedung, I., \& Rasmussen, J. (2002). Graphic representation of accident scenarios: Mapping system structure and the causation of accidents. Safety Science, 40, pp. 397-417.

Thompson, J., \& Garrett-Peltier, H. (2012).Report: The Economic Consequences of Cutting the Supplemental Nutrition Assistance Program. p.2. Retrieved September 29, 2015, from http://www.peri.umass.edu/fileadmin/pdf/published study/snap report.pdf

Underwood, P., and Waterson, P. (2014). Systems thinking, the Swiss Cheese Model and accident analysis: A comparative systemic analysis of the Grayrigg train derailment using the ATSB, Accimap and STAMP models. Accident Analysis and Prevention, 68, pp. 75-94.

Vicente, K. J., \& Christoffersen, K. (2006). The Walkerton E.coli Outbreak: A test of Rasmussen's framework for risk management in a dynamic society. Theoretical Issues in Ergonomics Science, 7(2), pp. 93-112.

Waterson, P.E. (2009), A systems ergonomics analysis of the Maidstone and Tunbridge Wells infection outbreaks. Ergonomics, 52, 10, 1196-1205. 
Waterson, P.E. (2014), Patient Safety Culture: Theory, Methods and Application. Farnham, UK: Ashgate.

Woo, D. M., \& Vicente, K. J. (2003). Socio-technical systems, risk management, and public health: Comparing the North Battleford and Walkerton outbreaks. Reliability Engineering and System Safety, 80(April 2001), pp. 253-269.

Xiong, Y., Xu, J., Bai, X., Wang, H., Xin, Y., Wei, R., Tang, X., Zhao, A., Sun, H., Zhang, W., Wang, Y., Xu, Y., Zhang, Z., \& Li, Q. (2015). Prevalence and characteristics of Shiga toxin-producing Escehrichia coli isolated from retail raw meats in China. International Journal of Food Microbiology, 200, pp. 31-38. 
Table 1: Key functions of Environmental Health Officers in the UK (Food Standards Agency, 2010)

\begin{tabular}{|c|c|}
\hline Functions & Details \\
\hline \multirow[t]{2}{*}{ Interventions at food establishments } & $\begin{array}{l}\text { Compliance with new and improved } \\
\text { legislation and any new central } \\
\text { government initiatives. }\end{array}$ \\
\hline & $\begin{array}{l}\text { Maintaining the establishment's profile, } \\
\text { number of interventions planned, number } \\
\text { of revisits to be made and an estimation of } \\
\text { resources required. }\end{array}$ \\
\hline Dealing with food complaints & $\begin{array}{l}\text { Investigation of food complaints and } \\
\text { keeping an account of the business } \\
\text { complained about. }\end{array}$ \\
\hline Food sampling & $\begin{array}{l}\text { According to regulations, it is mandatory } \\
\text { for EHOs to estimate the number of } \\
\text { samples that will be taken from an } \\
\text { establishment and carry out sampling. }\end{array}$ \\
\hline Food safety incidents & $\begin{array}{l}\text { In the event of there being a food safety } \\
\text { related incident, it is the Environmental } \\
\text { Health Officer's duty to comply with the } \\
\text { relevant Codes of Practice, estimate the } \\
\text { services and resources required. }\end{array}$ \\
\hline Providing advice to businesses & $\begin{array}{l}\text { After carrying out an inspection, it is the } \\
\text { EHO's duty to advice the business on any } \\
\text { required changes or answering any } \\
\text { queries, should the food business have } \\
\text { any. }\end{array}$ \\
\hline $\begin{array}{l}\text { Control and investigation of food related } \\
\text { infectious disease }\end{array}$ & $\begin{array}{l}\text { Investigation of food poisoning incidents } \\
\text { and outbreak control; estimation of } \\
\text { previous years' trends and resources } \\
\text { required. }\end{array}$ \\
\hline Liaison with other organisations & $\begin{array}{l}\text { The authorities must ensure that the steps } \\
\text { they use to carry out inspections and the } \\
\text { enforcement actions they have taken is } \\
\text { consistent with those of neighbouring local } \\
\text { authorities. }\end{array}$ \\
\hline
\end{tabular}


Table 2: Steps used to construct the Accimap (Branford et al., 2009)

\begin{tabular}{|c|c|}
\hline Step number & Details \\
\hline 1 & $\begin{array}{l}\text { Sections were made on a large sheet of } \\
\text { paper, with the headings of the various levels } \\
\text { on the left-hand side }\end{array}$ \\
\hline 2 & $\begin{array}{l}\text { Each accident was analysed separately and } \\
\text { negative outcomes to be analysed were } \\
\text { identified. The outcomes were now inserted } \\
\text { into the "Outcomes" level of the Accimap }\end{array}$ \\
\hline 3 & $\begin{array}{l}\text { A list of the causal factors was made. Causal } \\
\text { factors are factors which if prevented, would } \\
\text { probably have avoided the accident }\end{array}$ \\
\hline 4 & $\begin{array}{l}\text { The appropriate level for each of the causal } \\
\text { factors was identified based on the } \\
\text { guidelines provided in Table } 1 \text { by Branford et } \\
\text { al. (2009) }\end{array}$ \\
\hline 5 & $\begin{array}{l}\text { The causal factors were written on a sticky } \\
\text { note and then placed at the appropriate level } \\
\text { on the sheet of paper }\end{array}$ \\
\hline 6 & $\begin{array}{l}\text { The causal links were inserted, linking the } \\
\text { factors and hence demonstrating the } \\
\text { systemic errors }\end{array}$ \\
\hline 7 & $\begin{array}{l}\text { Using Microsoft Visio, the factors were } \\
\text { rearranged such that that related and causes } \\
\text { leading to the same outcome(s) were placed } \\
\text { close to each other, whether in the same } \\
\text { level or in the level(s) below }\end{array}$ \\
\hline
\end{tabular}

Reviewed by Rounaq Nayak and Patrick Waterson as mentioned in Section 2.2. 
Table 3: The proximal events leading to the E.coli 0157 outbreak in the Central belt Scotland in 1996 (The Pennington Group, 1997)

Adapted from The Pennington Group Report, 1997.

\begin{tabular}{|c|c|}
\hline Date & Event(s) \\
\hline 17 November 1996 & $\begin{array}{l}\text { People infected at a luncheon served at } \\
\text { Wishaw Old Parish Church. }\end{array}$ \\
\hline 22 November 1996 & $\begin{array}{l}\text { Possibility of an outbreak of food poisoning } \\
\text { due to E.coli O157 identified. }\end{array}$ \\
\hline 23 November 1996 & $\begin{array}{l}\text { Outbreak control team (OCT) formed by The } \\
\text { Scottish Office Department of Health } \\
\text { Advisory Group on Infection. }\end{array}$ \\
\hline 26 November 1996 & $\begin{array}{l}\text { The Scottish Office Department of Health } \\
\text { (SODoH) and the Agriculture, Environment } \\
\text { and Fisheries Department (SOAEFD) met } \\
\text { with the Health Board and the Council. }\end{array}$ \\
\hline 27 November 1996 & $\begin{array}{l}\text { Food Hazard Warning issued by the Scottish } \\
\text { Office. }\end{array}$ \\
\hline 28 November 1996 & $\begin{array}{l}\text { Detailed advice and guidelines for butchers } \\
\text { was issued by The Scottish Office through a } \\
\text { further Food Hazard Warning. } \\
\text { The Scottish Office attended the OCT } \\
\text { meetings as observers. } \\
\text { The Secretary of State for Scotland } \\
\text { announced in Parliament the establishment } \\
\text { of an Expert Group to "examine the } \\
\text { circumstances which led to the outbreak in } \\
\text { the central belt of Scotland and to advice on } \\
\text { the implications for food safety and the } \\
\text { general lessons to be learned. This group } \\
\text { was to be chaired by Professor Hugh } \\
\text { Pennington. }\end{array}$ \\
\hline 5 December 1996 & $\begin{array}{l}\text { The Crown Office announced that a Fatal } \\
\text { Accident Inquiry (FAI) would be held into the } \\
\text { deaths due to the outbreak. }\end{array}$ \\
\hline 10 January 1997 & $\begin{array}{l}\text { Mr John Barr charged with culpable and } \\
\text { reckless conduct arising from the alleged } \\
\text { supply of cooked meats. }\end{array}$ \\
\hline April 1997 & $\begin{array}{l}\text { The report on the circumstances leading to } \\
\text { the } 1996 \text { outbreak of infection with E.coli } \\
\text { O157 in Central Scotland, the implications } \\
\text { for food safety and the lessons to be learned } \\
\text { published. }\end{array}$ \\
\hline
\end{tabular}


Table 4: The proximal events leading to the E.coli 0157 outbreak in South Wales in 2005

Adapted from The Public Inquiry into the September 2005 Outbreak of E.coli O157 in South Wales, 2009.

\begin{tabular}{|c|c|}
\hline Date & Event(s) \\
\hline $1998-2005$ & $\begin{array}{l}\text { Contract awarded to John Tudor \& Son to } \\
\text { provide meat. }\end{array}$ \\
\hline 2001 & New line manager. \\
\hline 1 September 2003 & $\begin{array}{l}\text { New Principal and Senior Environmental } \\
\text { Health Officers appointed. }\end{array}$ \\
\hline Late 2003 & $\begin{array}{l}\text { New Procedures policy introduced by } \\
\text { Bridgend council. }\end{array}$ \\
\hline February 2004 & $\begin{array}{l}\text { Bridgend County Borough Council audited by } \\
\text { the Food Standards Agency (FSA). }\end{array}$ \\
\hline 16 August 2004 & $\begin{array}{l}\text { New Enforcement Policy introduced by } \\
\text { Bridgend council. }\end{array}$ \\
\hline 17 June 2005 & $\begin{array}{l}\text { Draft report provided by FSA to the Bridgend } \\
\text { County Borough Council. }\end{array}$ \\
\hline August 2005 & Senior EHO leaves post. \\
\hline 10 September 2005 & Possible start date of 3 possible cases. \\
\hline 16 September 2005 & $\begin{array}{l}\text { The admission of five children with watery, } \\
\text { blood-stained diarrhoea is reported by a } \\
\text { doctor at Prince Charles Hospital, Merthyr } \\
\text { Tydfil to the National Public Health Service } \\
\text { for Wales. } \\
\text { Outbreak declared. } \\
\text { Outbreak Control Team (OCT) formed. }\end{array}$ \\
\hline 4 October 2005 & $\begin{array}{l}\text { Mason Jones succumbs to infection due to } \\
\text { E.coli O157. }\end{array}$ \\
\hline 5 October 2005 & $\begin{array}{l}\text { The National Assembly for Wales sets up a } \\
\text { cross-party committee to consider the terms } \\
\text { of reference for a public inquiry. }\end{array}$ \\
\hline 7 November 2005 & Last date of registered case. \\
\hline 17 November 2005 & $\begin{array}{l}\text { Professor Hugh Pennington joins the } \\
\text { committee as the Chair. }\end{array}$ \\
\hline 14 December 2005 & $\begin{array}{l}\text { An investigator from the Veterinary } \\
\text { Laboratories Agency visited The Farm to } \\
\text { collect samples of bovine faeces and } \\
\text { bedding contaminated with bovine faeces. }\end{array}$ \\
\hline 20 December 2005 & Outbreak formally declared over. \\
\hline
\end{tabular}


Table 5: Explanation of the numbered factors in Figure 3

Factor Identification Number

1

\section{Interpretation}

It was too expensive to carry out a media awareness program and hence using this medium to inform the people was not a long term option.

The 1995 Regulations addressed only the concepts of HACCP and were less detailed in comparison to the 1994 Regulations.

The loopholes allowed small businesses exemption from certain parts of the 1994 Regulations and there was no direct legal requirement to implement the directives.

The Meat Hygiene Service (MHS) did not have any legal authority over transportation of meat to non-registered premises.

In addition to there being no resources earmarked for either food safety or environmental health purposes, educating food handlers in HACCP principles heavily depleted the EHOs resources.

Out of 600 qualified environmental health officers in Scotland, only 15 from Glasgow, 7 from Edinburgh and 3 from Moray were in food safety full time. Other EHOs were also tasked with other duties such as evaluating noise and air pollution, health and safety and housing.

In the 1970s there was a merger in the government departments; hence although not all senior managers were trained in food safety, they were still put in charge of this department.

Less than $50 \%$ of the butchers had a product recall system in place; only $11 \%$ had tested their recall system.

Poorly planned design and layout restricted the effective flow of meat and also led to the carcasses coming in contact with walls and floors.

There were three stages of cross contamination: (1) animal-animal, (2) animal-human and (3) human-human. 
The outbreak was declared on $22^{\text {nd }}$ November 1996 and the number of cases increased by $24^{\text {th }}$ November. In total there were 496 cases and 18 people died. 
Table 6: Explanation of the numbered factors in Figure 4

Factor Identification Number

\section{Interpretation}

As the auditing system was strictly systems based, quality of the inspections carried was not evaluated.

At the government level as the only target was to overcome legal barriers, the tender documents were not handed over to the Environmental Health Department for re-verification.

Although the audit was carried out in February 2004, the draft report wasn't sent to the local council for over a year $\left(17^{\text {th }}\right.$ June 2005).

There were multiple faulty approaches taken by the EHOs such as: (1) no system for red-flagging from previous visits, (2) not communicating with employees during visits, (3) overdue inspections, (5) no verification of records shown by Tudors and (6) lenient rating.

There was no written document that stated the role of each of the 4 authorities (Rhondda Cynon Taf, Bridgend, Caerphilly and Merthyr Tydfil County Borough Councils).

Meath Hygiene Regulations were neither enforced nor followed and the OVS disregarded regulations set by the Parliament and breached protocol by not inspecting every carcass post-mortem.

The HACCP plan was misleading and inaccurate and the EHOs were constantly lied to.

Single machinery was used for all cleaning all meats (raw and cooked) and all types of meat were handled at the vacuum packing machine and weighing scales.

Fresh and stale meat was mixed repeatedly for 4 years.

Although there were a separate set of clothes available while moving between raw and cooked meat processing areas, the workers did not change their clothes. 


\section{Figure 1: Accimap diagram format}

Adapted from Svedung and Rasmussen (2002).

SYSTEM LEVEL

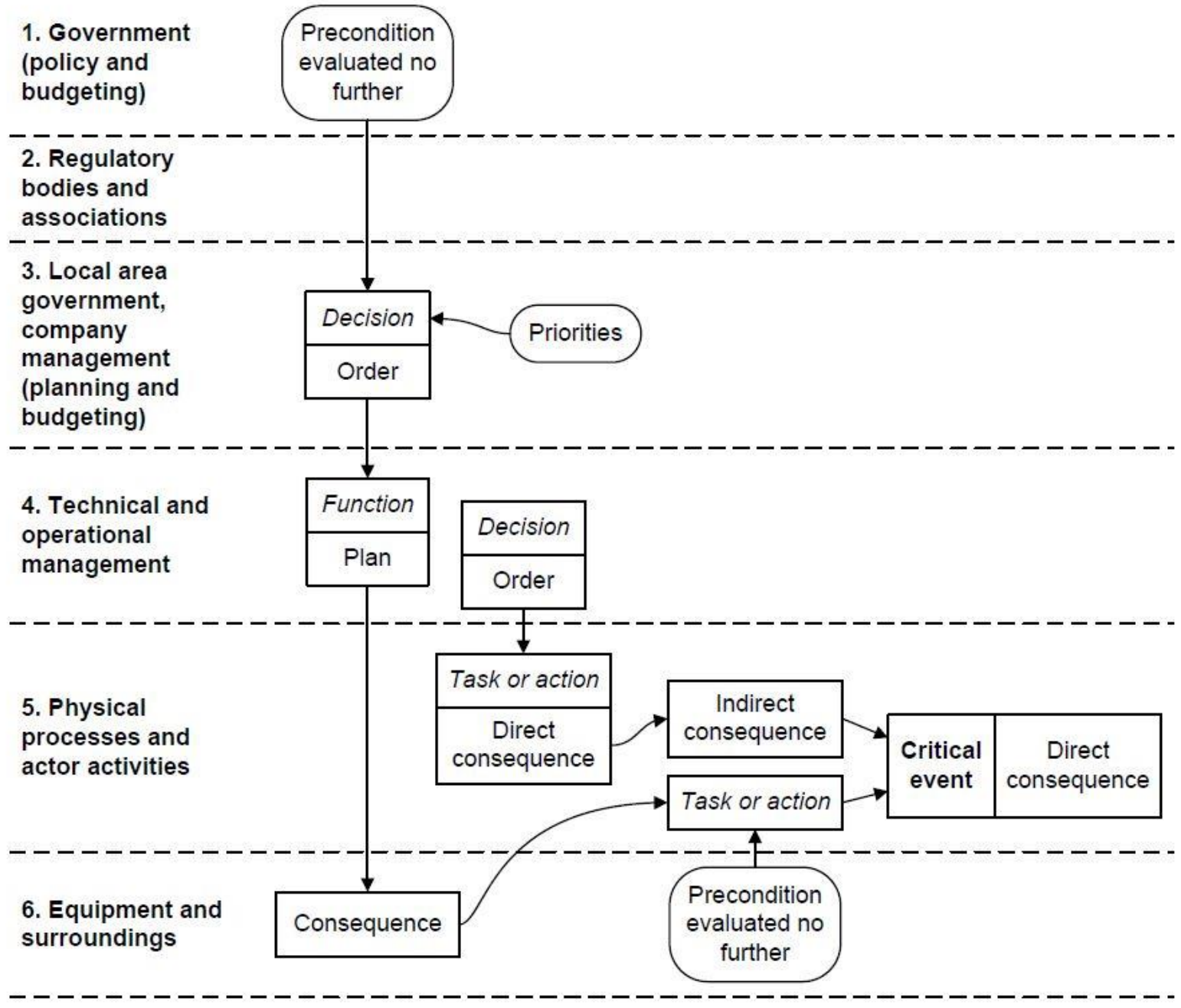


Figure 2 - Accimap diagram of the 1996 E.coli 0157 Outbreak

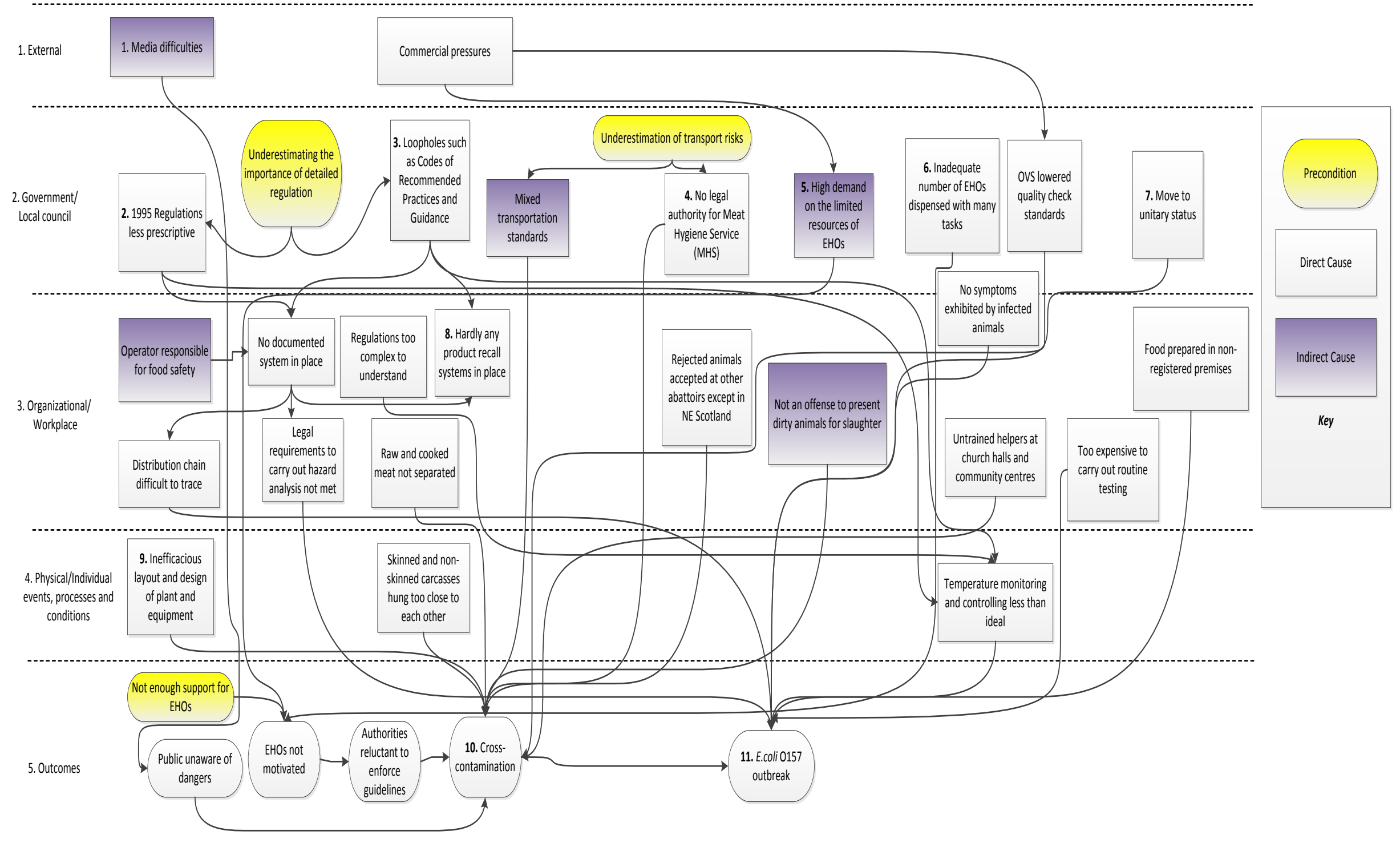


Figure 3 - Accimap diagram of the 2005 E.coli 0157 Outbreak

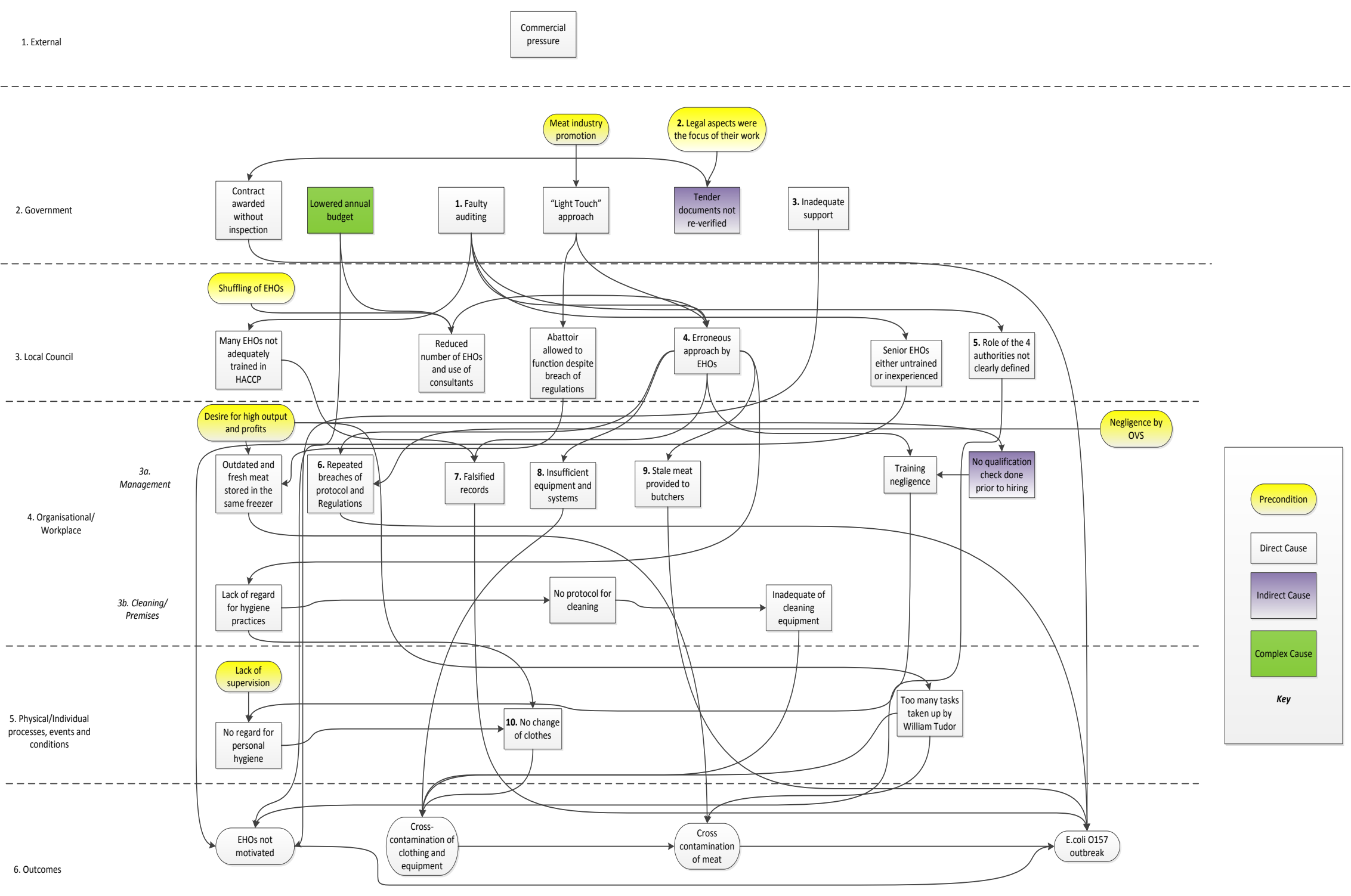


Figure 4 - Comparative analysis of the Scotland and South Wales outbreaks summarizing the factors that were common to both the accidents -
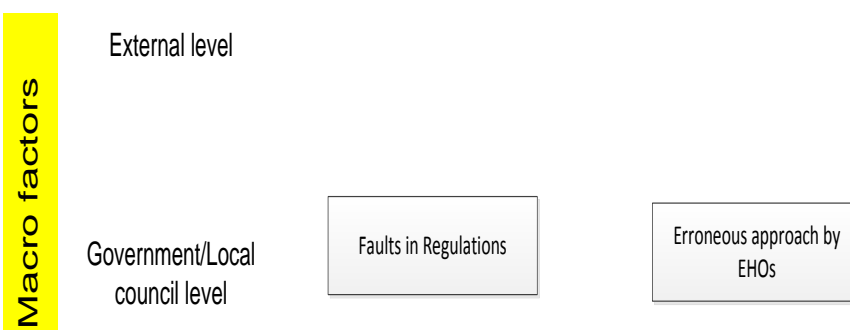

Commercial pressures

Faults in Regulations EHOs 


\section{Appendix 1}

\section{Acronyms used in the article}

\begin{tabular}{cc}
\hline Acronym & Full form \\
\hline EHO(s) & Environmental Health Officer(s) \\
HACCP & Hazard Analysis and Critical Control Point(s) \\
RSPH & Royal Society for Public Health \\
OCT & Outbreak Control Team \\
FSA & Food Standards Agency \\
OVS(s) & Official Veterinary Surgeon(s) \\
MHS & Meat Hygiene Service \\
\hline
\end{tabular}

1 'Outbreak' refers to either one of the outbreaks in particular and 'outbreaks' refers to either both the outbreaks or outbreaks in general. 